\title{
Design and Analysis of the Voltage Controller for the Non Isolated Boost DC-DC Convertor
}

\author{
Mohammadreza Modabberniar'1, Alireza Akoushideh', \\ Seyed yaser Fakhrmoosavi ${ }^{1}$ \\ ${ }^{1}$ Department of Electrical Engineering, Technical and Vocational \\ University, Rasht Branch, Rasht, Iran. \\ E-mails: mmodabernia@tvu.ac.ir (Corresponding author), \\ aakoushideh@tvu.ac.ir and Dr.fakhrmoosavi@tvu.ac.ir
}

\begin{abstract}
In this paper, a controller has been presented by the root locus method based on the state space average model of the boost switching regulator with all of the converter's parameters and uncertainties. In this model, the load current is unknown and the inductor, capacitor, diode and active switch are non ideal and have an on-state resistance. Furthermore, an on-state voltage drop has been considered for diode and active switch. By neglecting the load current and assuming the ideal elements the simplified model of the regulator has been caddied out. By these complete and simplified models, a step by step method has been proposed to design a single input single output (SISO), second order controller based on roots locus method. In this regard the controller's electronic circuit has been introduced by operational amplifiers. At the end, by simulation of the complete closed loop system in MATLAB Simulink environment and comparing its results by the results of the regulator and controller circuits in PLECS, the accuracy of the designed controller performance has been shown.
\end{abstract}

Keywords: Boost converter, root locus, state space average model.

\section{INTRODUCTION}

DC-DC power converters are those of the standard components of switching power supplies. Many converters have been applied and utilized on devices such as personal and portable computers, office equipments, space shuttles, satellite communication equipments, and DC motors drivers. The input of the converter is an unregulated DC voltage and its output is a regulated voltage greater or less than the input with the same or reverse polarity [1]. In these converters, the power switching function of power electronics related switches (mosfet, bipolar transistor, etc) has been used to achieve high efficiency. When these switches are on, their voltage drop is zero. On the other hand, their current is negligible when they are off. 
Therefore, the power losses of these components are always negligible. But, because of the non ideal nature of the switches, their on-state resistance, non zero sudden current and voltage in switching times, their power losses are always visible. This causes the efficiency of these converters to be about $70 \%$ to $95 \%$ in practice [2]. Among all kinds of the DC-DC converters, the boost type converter has been used in applications that require more output voltage than input. Controlling boost converter is more difficult than other types of buck, buck-boost regulators because this converter is non-minimum phase and has a right half plan zero. In other words, since the control input (duty cycle of pulse command) of this regulator is presented in both current and voltage equations the equations related to its state and control are more difficult [3]. The structure of DC-DC converters consists of two linear (inductor, capacitor, and resistive element) and nonlinear (diode and active switches) sections. Also, due to the use of the switching property of the power elements, the performance of these converters varies by time. So these converters are nonlinear and time varying systems. To design linear controllers, we need to obtain their small signal model based on the linearization method around a suitable working point [4]. The small signal analysis and the DC-DC converters controller design in frequency domain have been addressed in [5-6].

The main step in the precise and non-conservative study of the boost converter and its controller design is to have a complete model in which all of the system parameters (on state resistance of the diode and active switches, the resistance of the capacitor and the inductor and the uncertain load current flow) have been considered. The state space average model of the regulators comes back to Cuke and Middlebrock in late of 1970s [7]. Basu and Thomusco combined the boost converter model to the inductor and capacitor parasitic resistance and output current [8-9]. Naim and et.al reckoned only capacitor resistance and output current as parameters and designed a robust controller for the regulator [10]. He explicitly refers to the complexity of the full model and refuses to provide it in a parametric manner. Vorperin has provided the linear model of the ideal diode and switch as a pwm switch in the case of continuity and discontinuity [11]. He has a brief announcement of the effects of incorporated in and off states of the diode and switch on the pwm model [12]. In his Ph.D. dissertation, Remero presented the average state space model of the boost regulator in the presence of the capacitor and inductor resistances [13]. An average model is also introduced to pwm switch accompanied by switch and diode resistors and their voltage drops across the discontinuity conditions without providing the average state space model of the regulator [14]. The complete model of the boost converter has been presented in the presence of uncertainties regarding the voltage drop of the switching mode, the parasitic resistance of the components and the load current in [15]. 
In this paper, the boost converter model has been first introduced in the presence of all the system parameters. Then by eliminating some of the converter uncertainties, its transfer functions have been calculated from the output voltage to the input voltage and operating cycle. In the third section, the general controller structure and controller gain have been presented and adjusted respectively based on the roots locus method. The fourth part is dedicated to the simulation of the boost regulator closed loop system in the presence of all uncertainties and the designed controller. At the end, the electronic circuit of the controller has been designed by the operational amplifiers. The simulation of the closed loop system in MATLAB and simulation of its electronics circuit in PLECS show the similarity of the designed controller performance.

\section{BOOST CONVERTER STATE EQUATIONS IN THE PRESENCE OF ALL UNCERTAINTIES AND SYSTEM INPUTS}

The circuit of boost non-isolated DC-DC converter has been shown in Figure 1. $r_{m}, r_{d}, v_{M}$ and $v_{D}$ are the on-state resistances and voltage drops of the mosfet and diode respectively. The parasitic resistances of the capacitor and inductance have been modelled by $r_{c}$ and $r_{l}$ respectively. The states of the system are the inductor current and capacitor voltage $\left(\hat{x}=\left[\begin{array}{ll}\hat{i_{L}} & \hat{v}_{C}\end{array}\right]^{\prime}\right)$ and the plant has 4 inputs $\left(\hat{u}=\left[\begin{array}{llll}\hat{v_{G}} & \hat{i_{O}} & \hat{v}_{M} & \hat{v}_{D}\end{array}\right]^{\prime}\right)$ and 1 output $\left(y=\hat{v_{O}}\right)$. The ${ }^{\wedge}$ symbol represents the small deviations of the states, inputs and output.

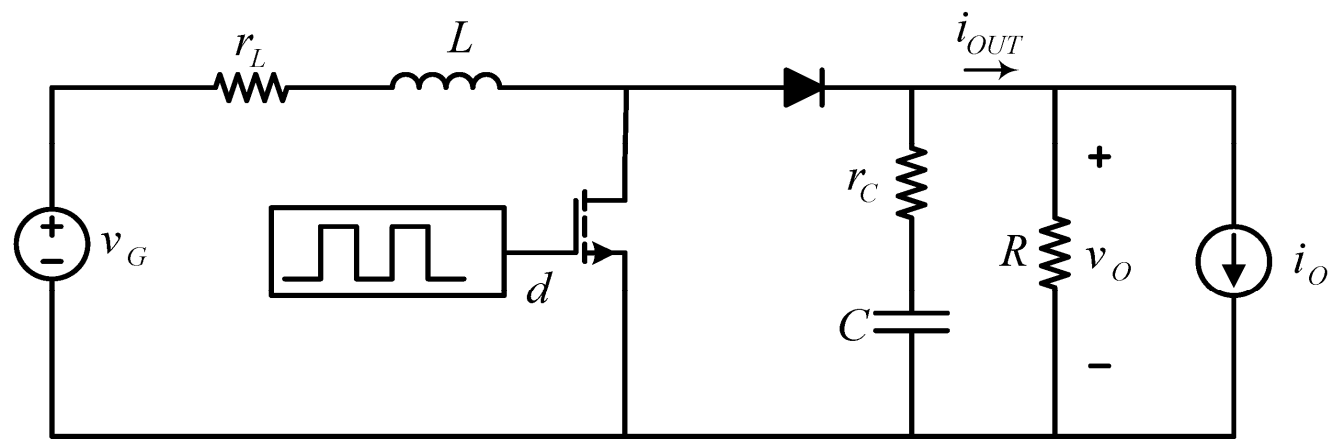

Figure 1. The circuit of boost non-isolated DC-DC converter.

The state-space average model of the boost non-isolated regulator with all the system uncertainties can be shown in the form of Equations (1) through (9) [15].

$\left\{\begin{array}{l}\dot{\hat{x}}=A \hat{x}+B \hat{u}+E \hat{d} \\ \dot{\hat{y}}=C \hat{x}+D \hat{u}+F \hat{d}\end{array} \quad \hat{x}=\left[\begin{array}{ll}\hat{i_{L}} & \hat{v_{C}}\end{array}\right]^{\prime} \quad \hat{u}=\left[\begin{array}{llll}\hat{v_{G}} & \hat{i_{O}} & \hat{v_{M}} & \hat{v}_{D}\end{array}\right]^{\prime}\right.$

Where 
$A=\left[\begin{array}{cc}\frac{-\left[\left(R r_{L}+r_{L} r_{c}+R r_{m}+r_{m} r_{c}\right)+\left(R r_{c}+R r_{d}+r_{c} r_{d}-R r_{m}-r_{m} r_{c}\right) D^{\prime}\right]}{L\left(R+r_{c}\right)} & \frac{-R D^{\prime}}{L\left(R+r_{c}\right)} \\ \frac{R D^{\prime}}{\left(R+r_{c}\right) C} & \frac{-1}{\left(R+r_{c}\right) C}\end{array}\right]$

$B=\left[\begin{array}{cccc}\frac{1}{L} & \frac{R r_{c} D^{\prime}}{\left(R+r_{c}\right) L} & \frac{-1+D^{\prime}}{L} & \frac{-D^{\prime}}{L} \\ 0 & \frac{-R}{\left(R+r_{c}\right) C} & 0 & 0\end{array}\right]$

$C=\left[\begin{array}{ll}\frac{R r_{c} D^{\prime}}{R+r_{c}} & \frac{R}{R+r_{c}}\end{array}\right]$

$D=\left[\begin{array}{llll}0 & \frac{-R r_{c}}{R+r_{c}} & 0 & 0\end{array}\right]$

$E=\left[\begin{array}{c}\frac{K+R^{2} D^{\prime}}{L \Delta} V_{G}+\frac{K\left(R^{2} D^{\prime}+R r_{c} D^{\prime}\right)+R^{2}\left(R^{2} D^{\prime 2}+R r_{c} D^{\prime 2}-\Delta\right)}{L\left(R+r_{c}\right) \Delta} I_{O}-\frac{\left(1-D^{\prime}\right)\left(K+R^{2} D^{\prime}\right)}{L \Delta} V_{M}-\frac{\left(K D^{\prime}+R^{2} D^{\prime 2}\right)}{L \Delta} V_{D} \\ \frac{-R}{C \Delta} V_{G}+\frac{-R^{2} D^{\prime}}{C \Delta} I_{O}-\frac{R\left(1-D^{\prime}\right)}{C \Delta} V_{M}-\frac{R D^{\prime}}{C \Delta} V_{D}\end{array}\right]$

$F=\left(C_{1}-C_{2}\right) X=\frac{-R r_{c}}{\Delta} V_{G}+\frac{-R^{3} r_{c} D^{\prime}}{\left(R+r_{c}\right) \Delta} I_{O}+\frac{R r_{c}\left(1-D^{\prime}\right)}{\Delta} V_{M}+\frac{R r_{c} D^{\prime}}{\Delta} V_{D}$

Where

$K=R r_{c}+R r_{d}+r_{d} r_{c}-r_{c} r_{m}-R r_{m}$

And

$$
\Delta=\left(r_{L}+r_{m}\right)\left(R+r_{c}\right)+\left(R r_{c}+R r_{d}+r_{c} r_{d}-R r_{m}-r_{m} r_{c}\right) D^{\prime}+R^{2} D^{\prime 2}
$$

A simplified state-space model of the DC-DC non-isolated boost converter can be derived by neglecting some system uncertainties $\left(i_{O}=r_{l}=r_{c}=r_{m}=r_{d}=0\right)$.

$\left\{\begin{array}{l}\dot{\hat{x}}=A \hat{x}+B \hat{\imath}+E \hat{d} \\ \dot{\hat{y}}=C \hat{x}+D \hat{u}+F \hat{d}\end{array} \quad \hat{x}=\left[\begin{array}{ll}\hat{i}_{L} & \hat{v}_{C}\end{array}\right]^{\prime} \quad \hat{u}=\hat{v}_{G}\right.$

Where

$$
A=\left[\begin{array}{cc}
0 & \frac{-D^{\prime}}{L} \\
\frac{D^{\prime}}{C} & \frac{-1}{R C}
\end{array}\right], B=\left[\begin{array}{l}
\frac{1}{L} \\
0
\end{array}\right], C=\left[\begin{array}{ll}
0 & 1
\end{array}\right], D=0, E=\left[\begin{array}{c}
\frac{V_{G}}{L D^{\prime}} \\
\frac{-V_{G}}{R C D^{\prime 2}}
\end{array}\right], F=0
$$

Therefore the transfer functions of the regulator from the output voltage to the input voltage and duty cycle can be calculated. The Equation (12) and Equation (13) show these transfer functions respectively. 


$$
\begin{aligned}
& \frac{\hat{v}_{O}}{\hat{v}_{G}}=\frac{\frac{D^{\prime}}{L C}}{S^{2}+\left(\frac{1}{R C}\right) S+\left(\frac{D^{\prime 2}}{L C}\right)} \\
& \frac{\hat{v}_{O}}{\hat{d}}=\frac{\frac{V_{G}}{L C}\left[1-\left(\frac{L}{R D^{\prime 2}}\right) S\right]}{S^{2}+\left(\frac{1}{R C}\right) S+\left(\frac{D^{\prime 2}}{L C}\right)}
\end{aligned}
$$

\section{DESIGNING THE BOOST CONVERTER CONTROLLER BASED ON THE ROOT LOCUS METHOD}

The root locus is a graphical method for locating the poles of the closed loop system in the desired points based on the locations of the loop transfer function poles, zeros and varying its gain. In practice, only by gain regulation, it is not possible to achieve suitable locations for dominant poles of the closed loop systems (there is a lack of access to optimal performance). In this case, we need to compensate the system by moving the poles of the closed loop to suitable locations. By adding poles and zeros to the loop transfer function, the root locus of the closed loop system has been changed in order to achieve the desired performance and stability. In other words, the compensator changes the position of the loop transfer function poles and zeros so that a dominant pair of roots can be obtained for the close loop characteristic equation.

The root locus of the close loop system makes it possible to reach the overall controller structure and fine tuning the controller gain parameter. Figure 2 shows the block diagram of the convertor closed loop system with the output voltage feedback and $K(s)$ controller in the simplified system. The $B$ block represents the ratio of the voltage divider. This potentiometer has been used for sampling the output voltage. The amount of $B$ is less than 1 and is independent of frequency due to its resistance structure.

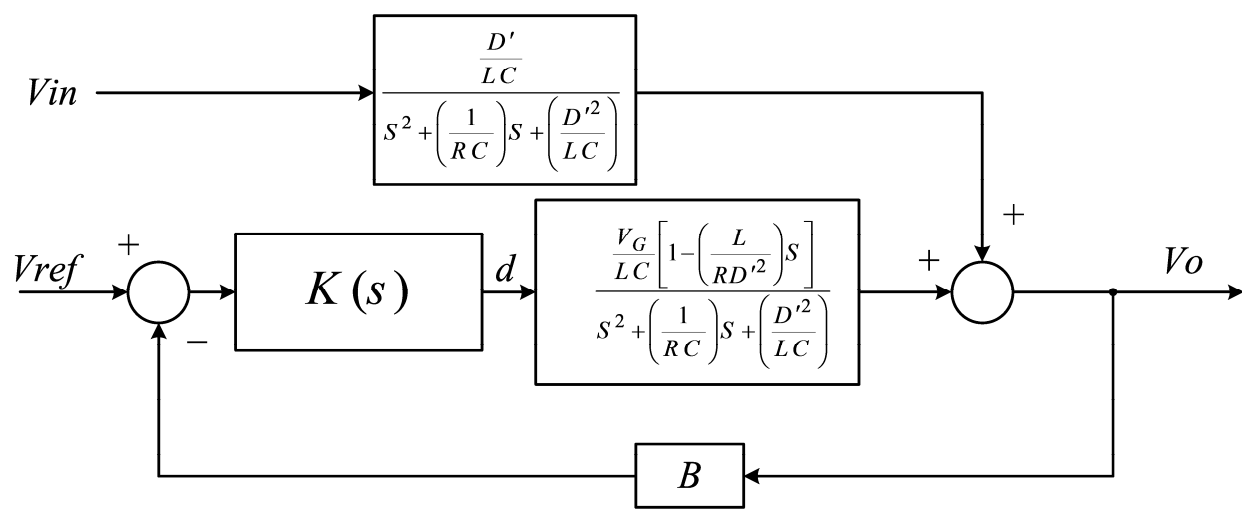

Figure 2. The block diagram of the convertor close loop system with the output voltage feedback and $K(s)$ controller in the simplified system. 
Assume that the controller in the simplest form is a proportional amplifier with the gain $K(s)=K_{p}$. The root locus of the converter closed loop system with this proportional controller $\left(K_{p}\right)$ and negative feedback $(B=1)$ from the output Voltage $\left(v_{o}\right)$ to the duty cycle $(D)$ has been shown in Figure 3 and Figure 4 for two real negative roots and two complex $j \omega$ left hand side roots of the boost converter transfer function respectively. These figures reflect that the roots of the closed loop characteristic equation are in the left hand side of the $j \omega$ axis for some of the $K_{p}$ values and the closed loop system can be stable. Therefore, the system seems to be compensated by a proportional controller and does not require any other compensation.

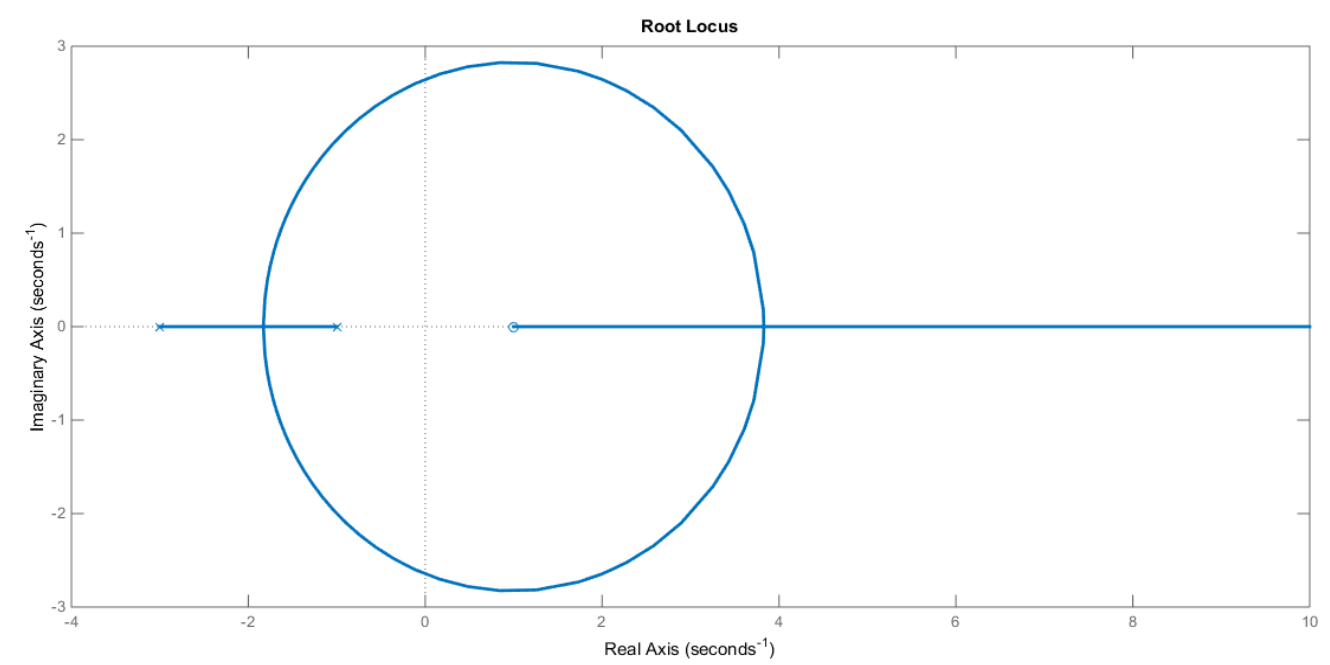

Figure 3. Root locus of the closed loop system of boost converter with proportional controller and two real negative roots.

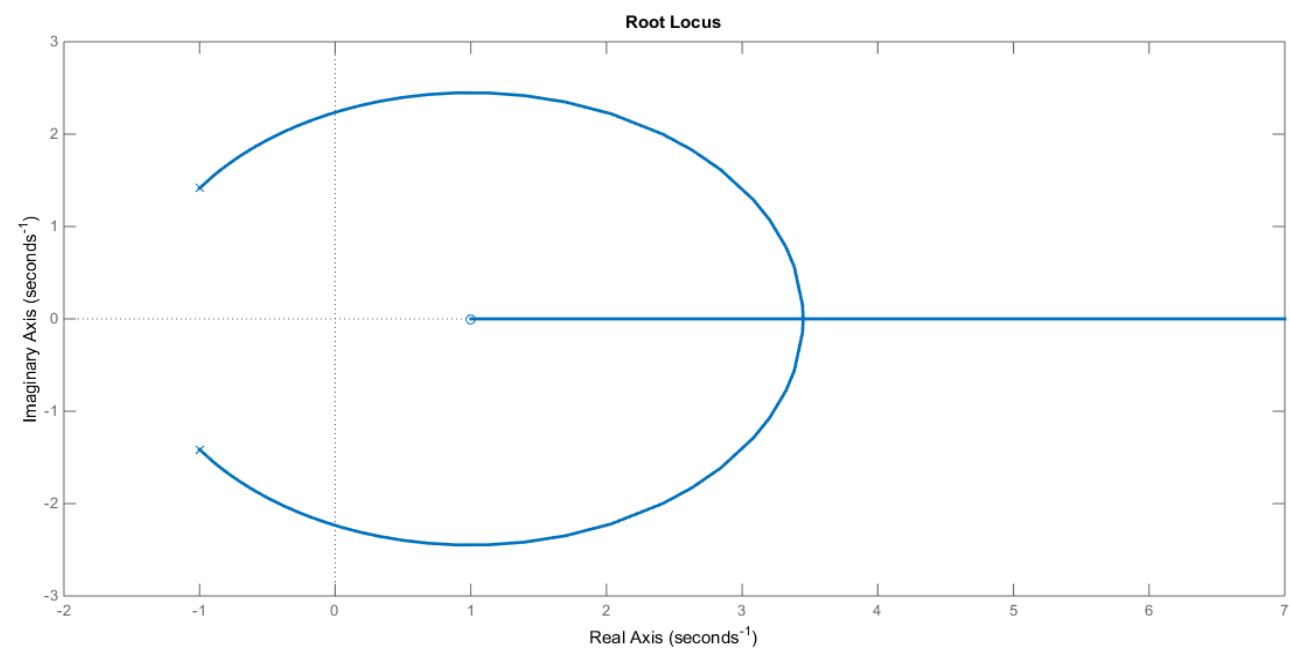

Figure 4. Root locus of the closed loop system of boost converter with proportional controller and two complex $j \omega$ left hand side roots. 
But the fact is that under these circumstances, the roots of the closed loop characteristic equation are closely related to the values of the open loop poles. Accordingly, the locations of the loop poles change the characteristic of the closed loop systems. On the other hand, according to the Equation (12) and Equation (13) the values of the loop transfer function poles depend on the load resistance and the nominal value of the duty cycle which can easily be increased and decreased in the circuit. As a result, changing the parameters will alter the state of the converter transfer function and consequently, the characteristic of the closed loop system. Also, the loop transfer function with the $K_{p}$ controller has no pole in origin. In other words, the system type with a proportional controller is zero and the permanent state error of the closed loop system, in response to step disturbance, cannot be zero. As a consequence, we have considered the controller with the transfer function of Equation (14) to achieve the following targets.

$$
K(S)=\frac{k(S+z)}{S(S+p)}
$$

1. The steady state error of the system, in response to the unit disturbance, must be zero. So, the loop transfer function of the system or the multiplication of the converter and controller transfer function must be at least order 1 . On the other hand, the controller must have a pole on the origin.

2. Since the open loop transfer function of the system (Equation (13)) has a negative gain; thus, to have a 180 degree for the angle of asymptotic branches of the closed loop system; a zero with the value of $(-z)$ has been chosen on the left half plan. The size of this zero must be large (the controller zero must be far from the $j \omega$ axis) so that it can absorb the two main poles of the converter (real or complex) toward itself; therefore, the closed loop system has not been affected by these two variable poles

3. A pole in the left half plan with the value of $-p$ has been chosen for the controller. This pole must be closer to the $j \omega$ axis toward the two poles of the converter (the roots of the Equation (12) or Equation (13) denominators). In other words, the two dominant poles of the closed loop system where they go toward the $j \omega$ axis by increasing the gain, can be considered by two controller poles.

\section{SELECTING THE CONTROLLER PARAMETERS}

To investigate the performance of the controller, the root locus curves of the closed loop system have been drawn based on the position of the right half plan zero, the hypothetical position of the two left poles and the transfer function with negative gain of converter transfer function in Figures 5 to 
Figure 14 respectively. The root locus of Figures 5, 10, 11 and 14 are not favourable because the two poles of the converter are pulled to the right half plan. Since the function of convertor is changed by input, load, and duty cycle, the performance of the closed loop system is very sensitive. Henceforth, we consider the following steps for choosing controller coefficients until the position of the closed loop poles have been influenced by position of the controller poles.

1. The open loop poles of the regulator have been determined by the complete boost steady state equations. Then the minimum and maximum distance of them have been calculated from the $j \omega$ axis.

2 . The zero of the controller must absorb the regulator poles. Therefore, the parameter of the zero $(z)$ has been selected for 10 times larger than the maximum distance of step1.

3 . The pole of the controller $(p)$ is chosen smaller than the minimum distance of step 1 until the performance of the closed loop system does not get affected by the converter pole. This pole should not be diminished because it will affect the position of the dominant poles of the closed loop system and the system settling time has been increased by shrinking their distances from the $j \omega$ axis.

4. After determining the general structure of the controller, its gain parameter can be obtained by plotting the root locus curve of the closed loop system in the presence of the controller. The gain parameter has been chosen to reach the damping ratio of $\xi=0.7$ or 5 percent overshoot.

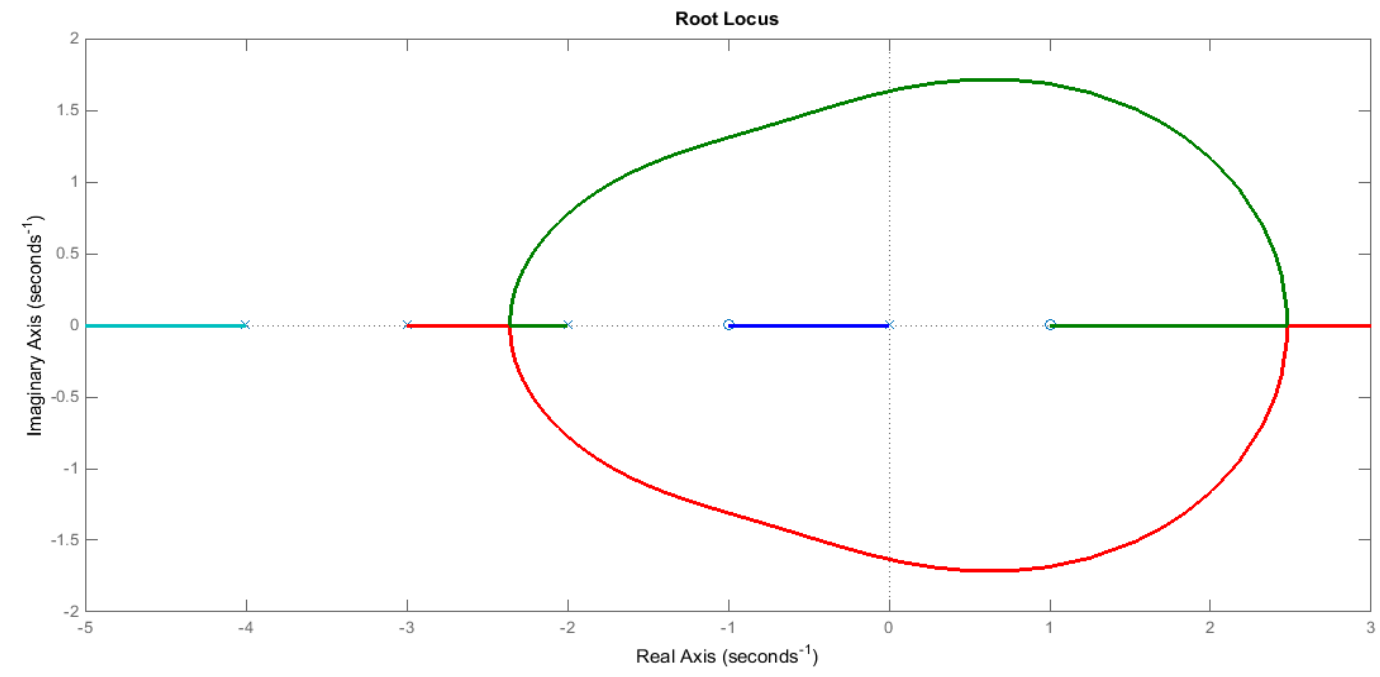

Figure 5. The poles of the converter are real and the poles of the converter are between the zero and pole of the controller. 


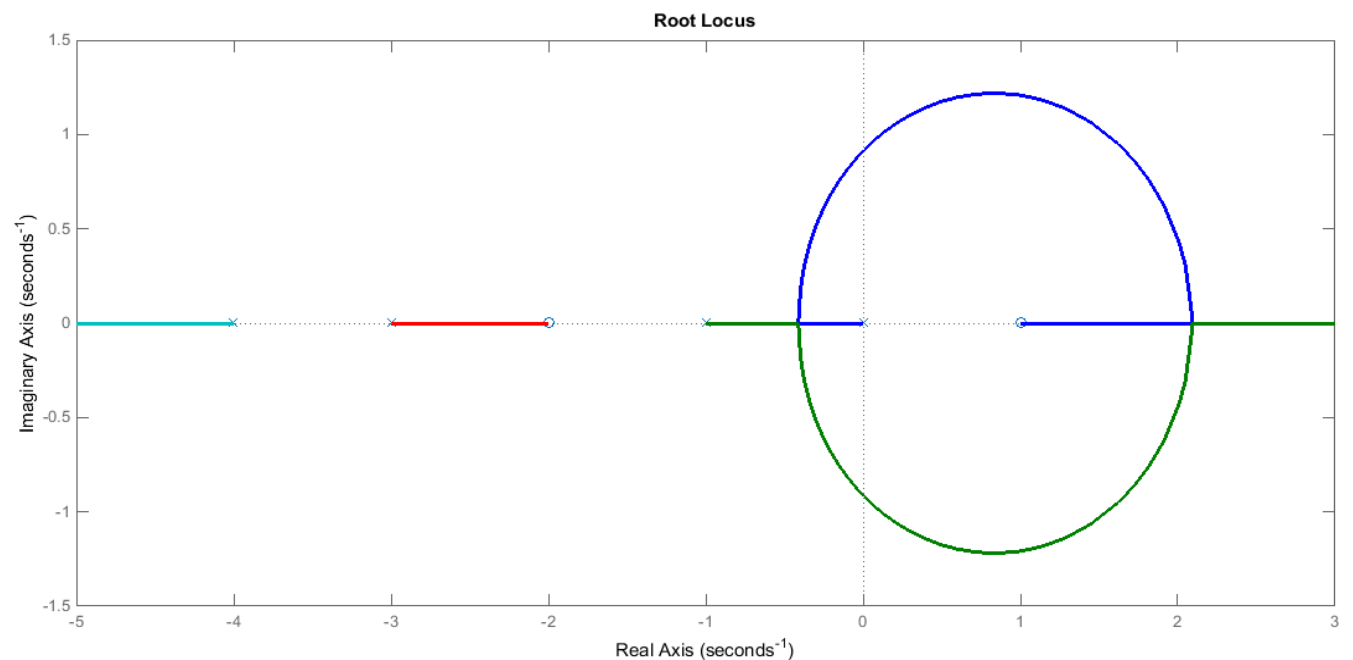

Figure 6. The poles of the converter are real and the controller zero is between the converter poles and the controller pole locates after the poles of the converter.

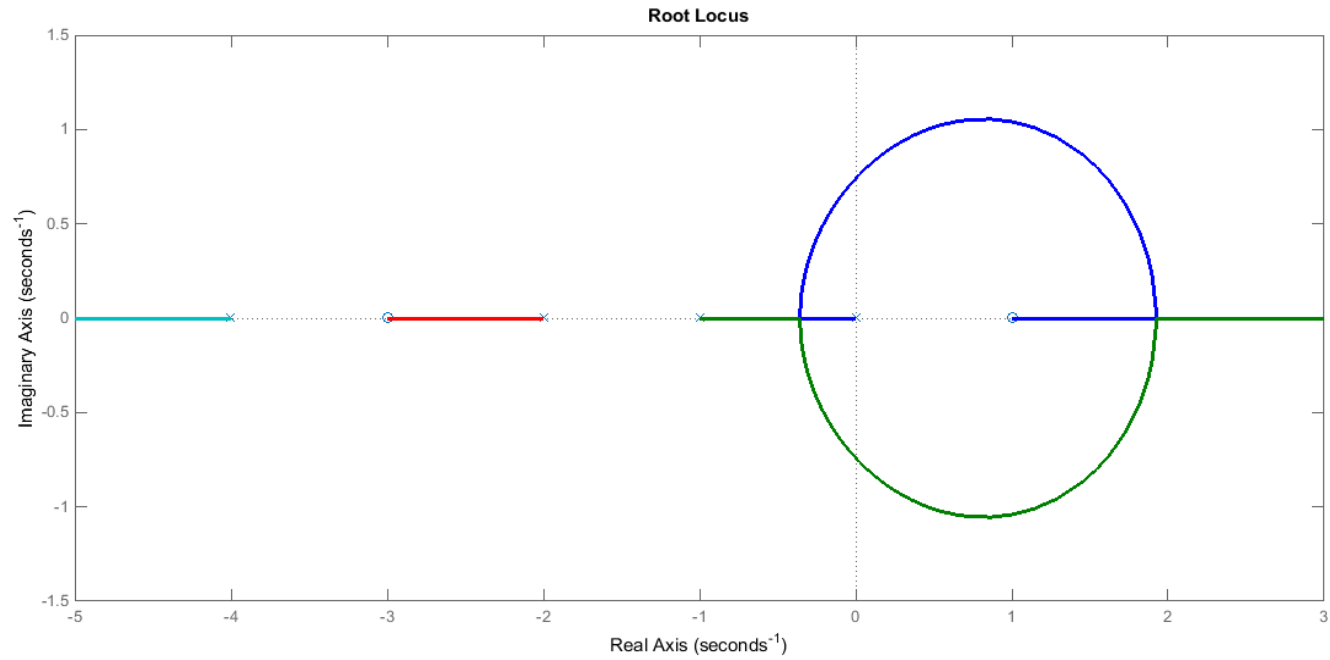

Figure 7. The poles of the converter are real and the controller pole locates before the converter poles and the controller zero is between the converter poles.

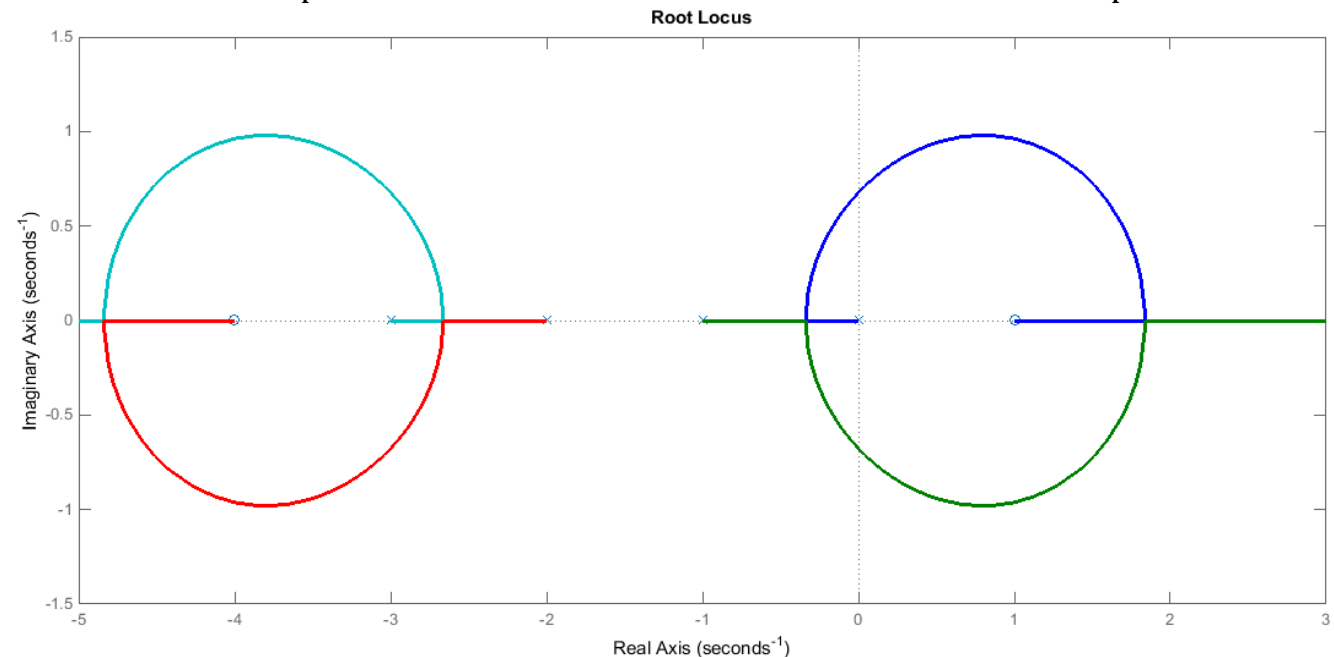

Figure 8. The poles of the converter are real and the controller pole is before the converter poles and the controller zero locates after the poles of the converter. 


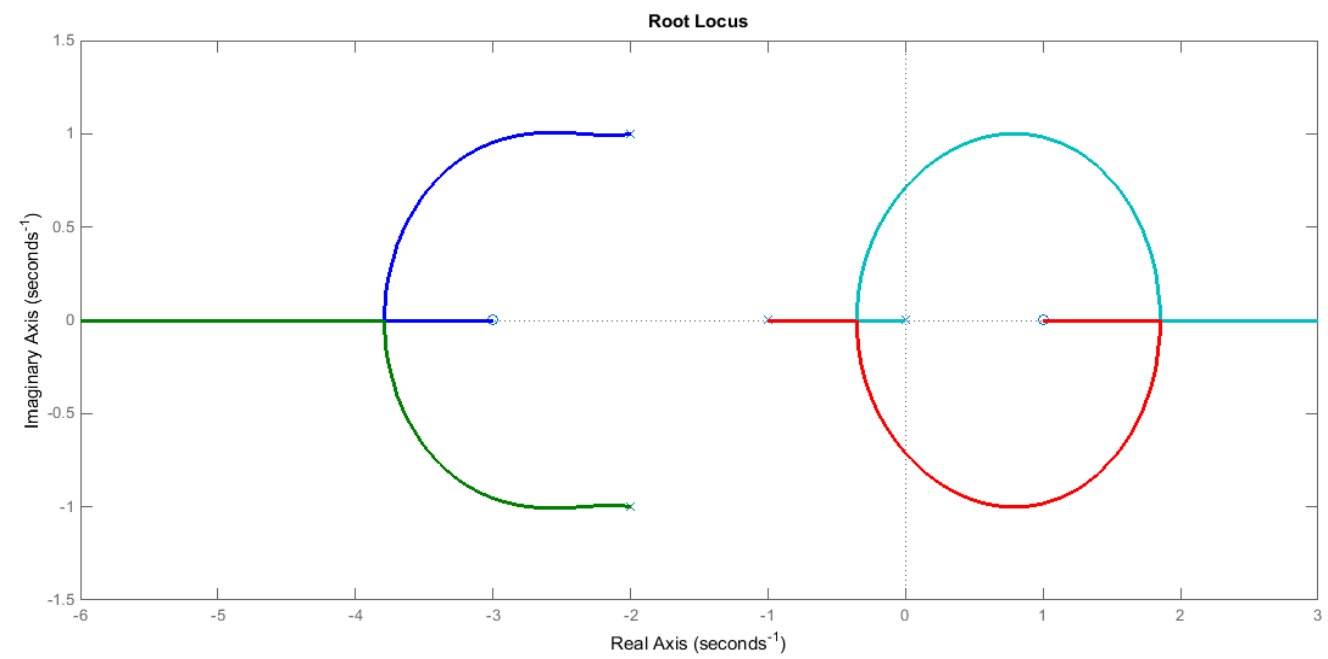

Figure 9. The poles of the converter are complex and the poles of the converter locate between the zero and pole of the controller and the controller's pole is closer to the $j \omega$ axis.

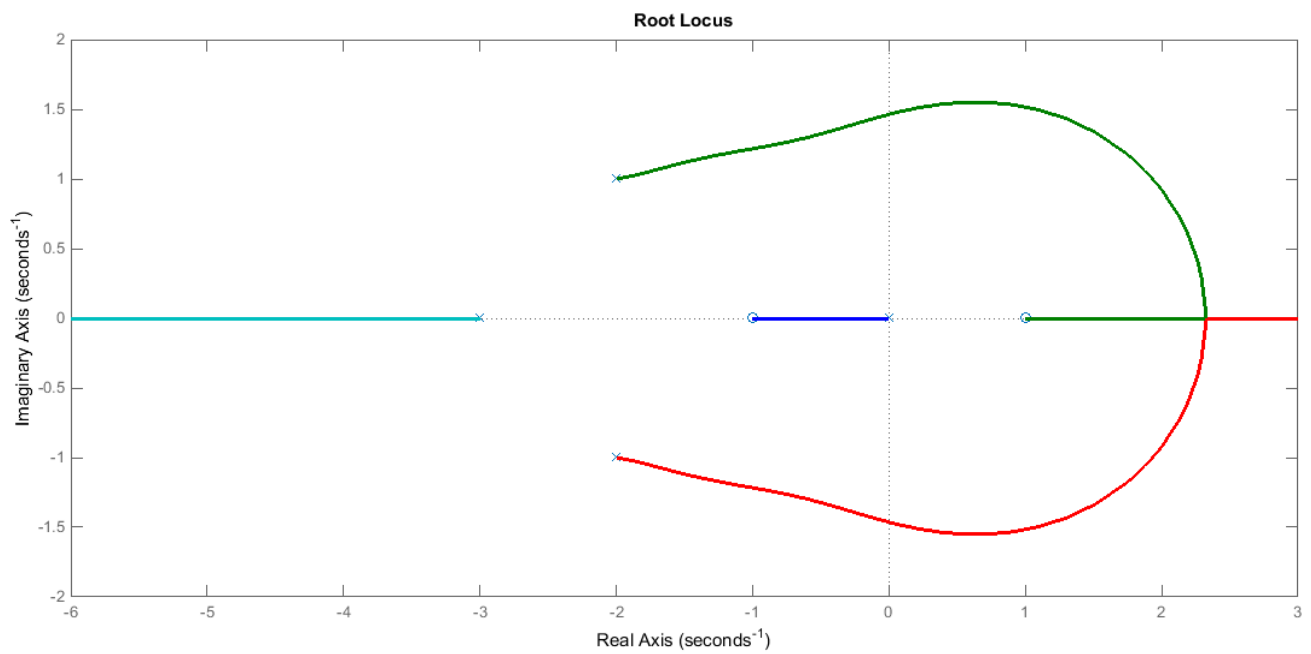

Figure 10. The poles of the converter are complex and the poles of the converter are between the zero and pole of the controller and the controller's zero is closer to the $j \omega$ axis.

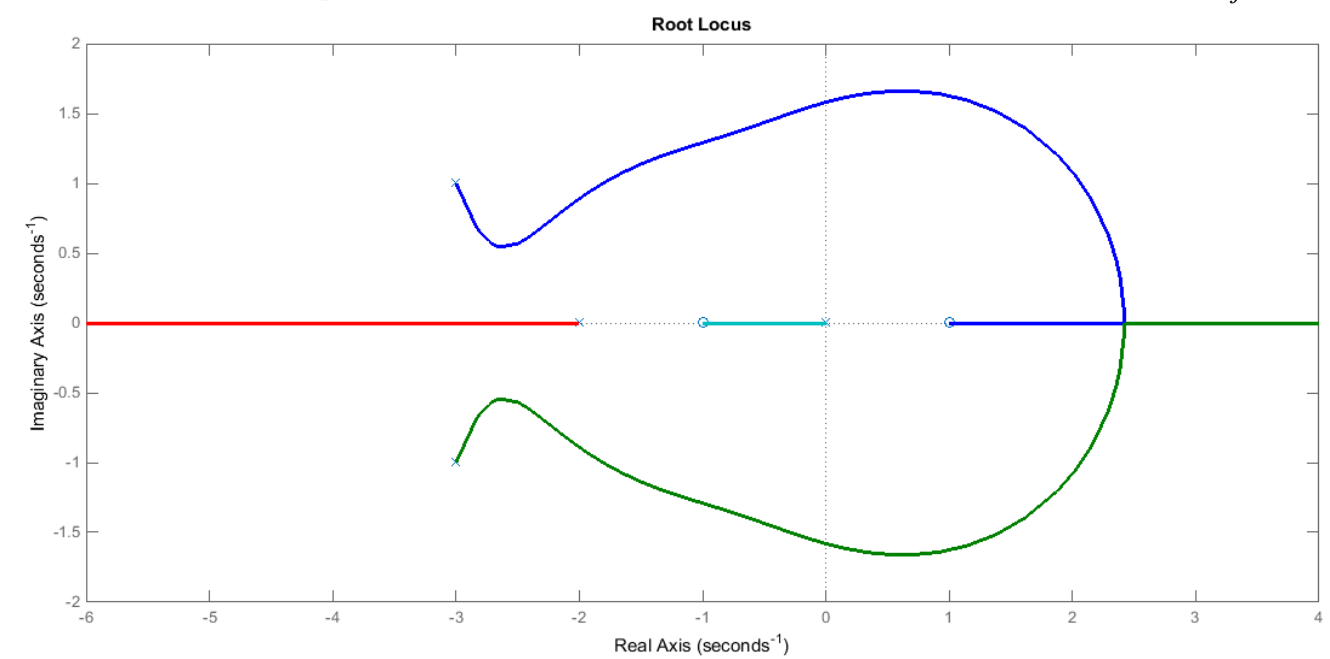

Figure 11. The poles of the converter are complex and the poles of the converter locate after the zero and pole of the controller and the controller's zero is closer to the $j \omega$ axis. 


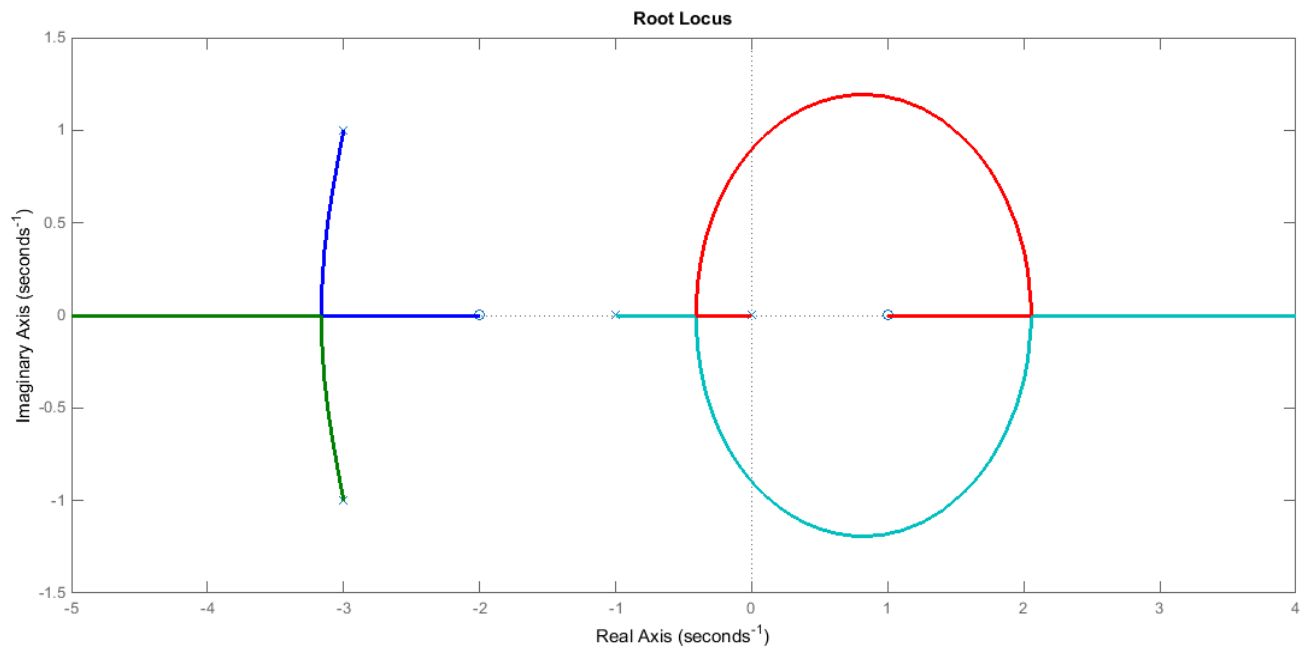

Figure 12. The poles of the converter are complex and the poles of the converter locate after the zero and pole of the controller and the controller's pole is closer to the $j \omega$ axis.

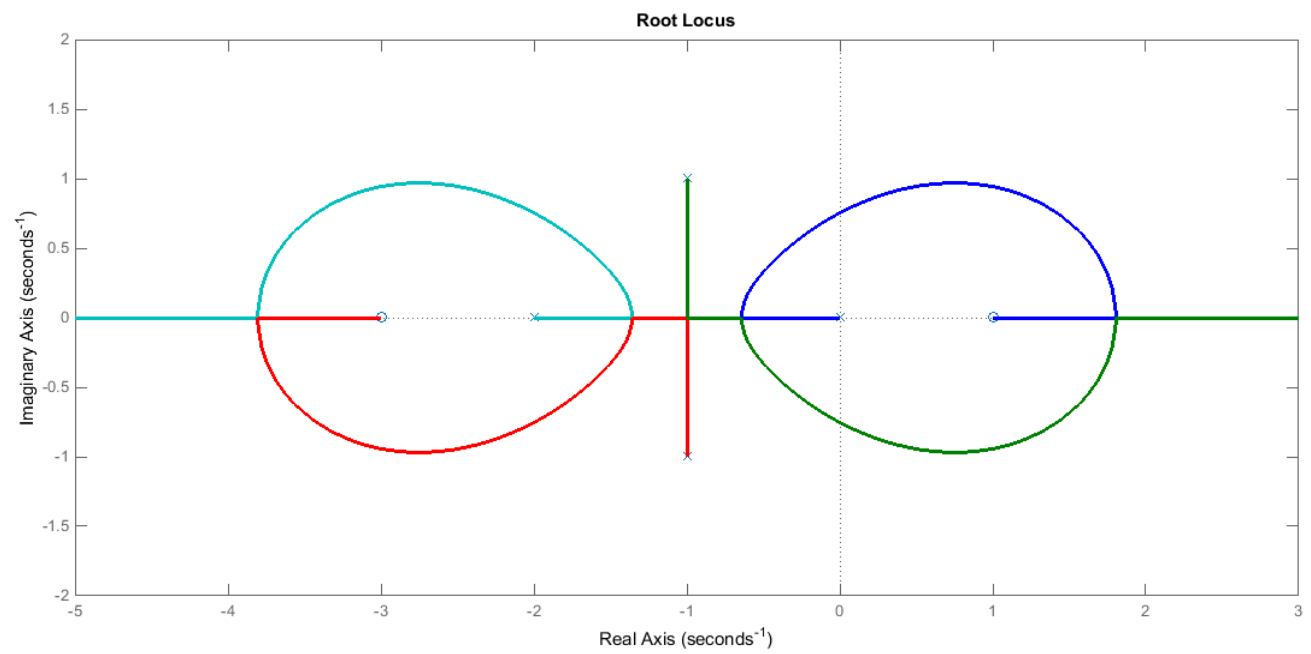

Figure 13. The poles of the converter are complex and the poles of the converter locate before the zero and pole of the controller and the controller's pole is closer to the $j \omega$ axis.

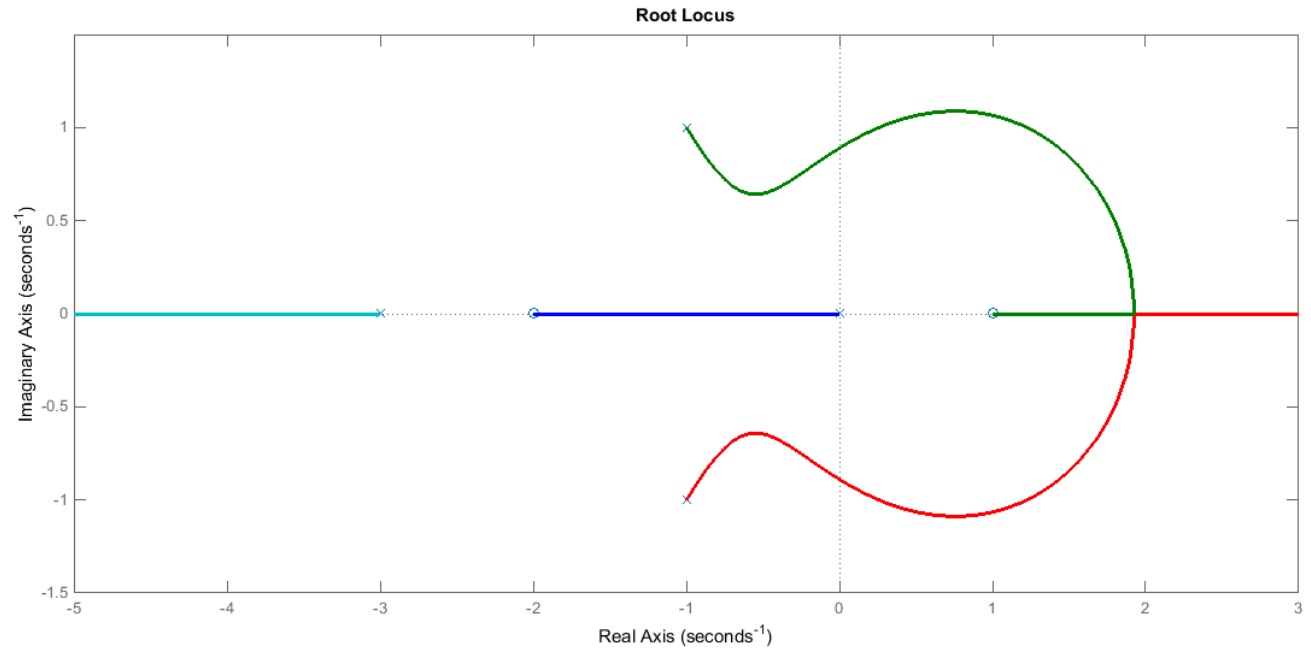

Figure 14. The poles of the converter are complex and the poles of the converter locate before the zero and pole of the controller and the controller's zero is closer to the $j \omega$ axis. 


\section{DESIGHNING THE ELECTRIC CIRCUIT OF DESIGNED CONTROLLER}

The electronic circuit of Figure 15 has been used to implement the designed controller. The transfer function of this circuit is:

$$
\frac{v_{O}}{v_{i}}=\frac{R_{1}\left(1+R_{2} C_{2} S\right)}{R R_{3} C_{2} S\left(1+R_{1} C_{1} S\right)}=\frac{\frac{R_{2}}{R R_{3} C_{1}}\left(S+\frac{1}{R_{2} C_{2}}\right)}{S\left(S+\frac{1}{R_{1} C_{1}}\right)}
$$

The Equation (14) and Equation (15) are equivalent, therefore we must have:

$$
\begin{aligned}
& z=\frac{1}{R_{2} C_{2}} \Rightarrow R_{2} C_{2}=\frac{1}{z} \\
& p=\frac{1}{R_{1} C_{1}} \Rightarrow R_{1} C_{1}=\frac{1}{p} \\
& k=\frac{R_{2}}{R R_{3} C_{1}}=\frac{R_{1} R_{2} p}{R_{3} R}
\end{aligned}
$$

By choosing the desired initial values for $C_{1}, C_{2}$ and $\mathrm{R}$, the value of the resistances $R_{1}, R_{2}$ and $R_{3}$ can be obtained by Equations (16), (17) and (18) respectively.

\section{DESIGN AND IMPLEMENTATION OF THE CONTROLLER FOR AN ACTUAL BOOST CONVERTER}

Figure 16 shows a boost converter in continuous current mode that converts the $12 \mathrm{~V}$ car battery voltage, to the $19 \mathrm{~V}$ voltage of a laptop [10]. The specifications of the circuit are $v_{O}=19 \mathrm{~V}, v_{G}=12 \mathrm{~V}, C=220 \mu \mathrm{F}, L=200 \mu \mathrm{H}$, $R=44 \Omega$. Diode, mosfet, capacitor and inductor parasitic resistors are $r_{d}=r_{m}=r_{c}=0.1 \Omega$ and $r_{l}=0.2 \Omega$. Diode voltage drop is $v_{D}=0.71 \mathrm{~V}$ and the onstate mosfet voltage drop is considered $v_{M}=0.075 \mathrm{~V}$. Based on the amounts of $v_{G}$ and $v_{O}$, the duty cycle of the converter has an average value of $D=1-\left(v_{G} / v_{O}\right)=0.37 \mathrm{~V}$.

Based on the complete model of boost converter (Equation (1) to Equation (9)), the two poles of the regulator locate at j2879.6 \pm 9.959 where their distance from the $j \omega$ axis is 959.1. Therefore, the size of controller pole ( $p$ ) has chosen the 90 percent of this value $(p=863)$. Also, the size of the controller zero $(z)$ has been selected 10 times greater than the distance of the converter poles from $j \omega$ axis $(z=9590)$.

In other respect, the controller will have the following structure, where its gain $(k)$ has been determined based on the root locus of the closed loop transfer function from the output voltage $\left(v_{O}\right)$ to the duty cycle deviation $(d)$. 


$$
K(S)=\frac{k(S+9590)}{S(S+863)}
$$

Root locus of the closed-loop system based on this controller and the complete model of the boost converter (equation 1) has been shown in Figure 17. Figure 18 shows the zoom of this root locus around the origin. By choosing $k=8.72$, the overshoot of the system is 3.46 percent.

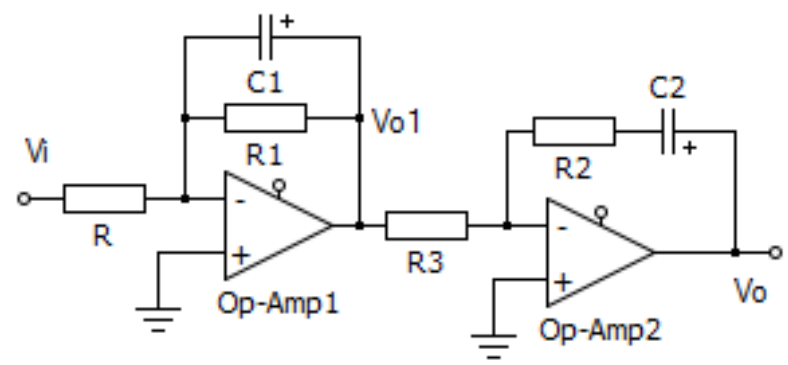

Figure 15: The electronic circuit of the designed controller.

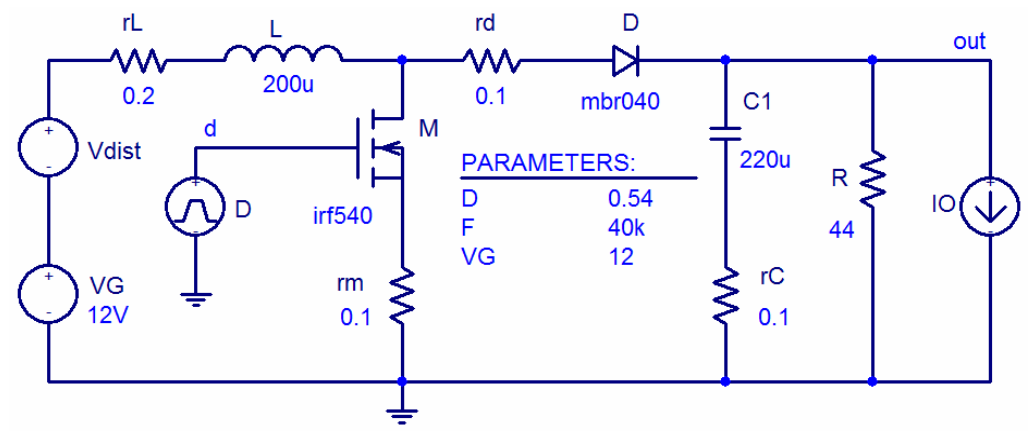

Figure 16: A $12 \mathrm{~V}$ to $19 \mathrm{~V}$ boost converter [10].

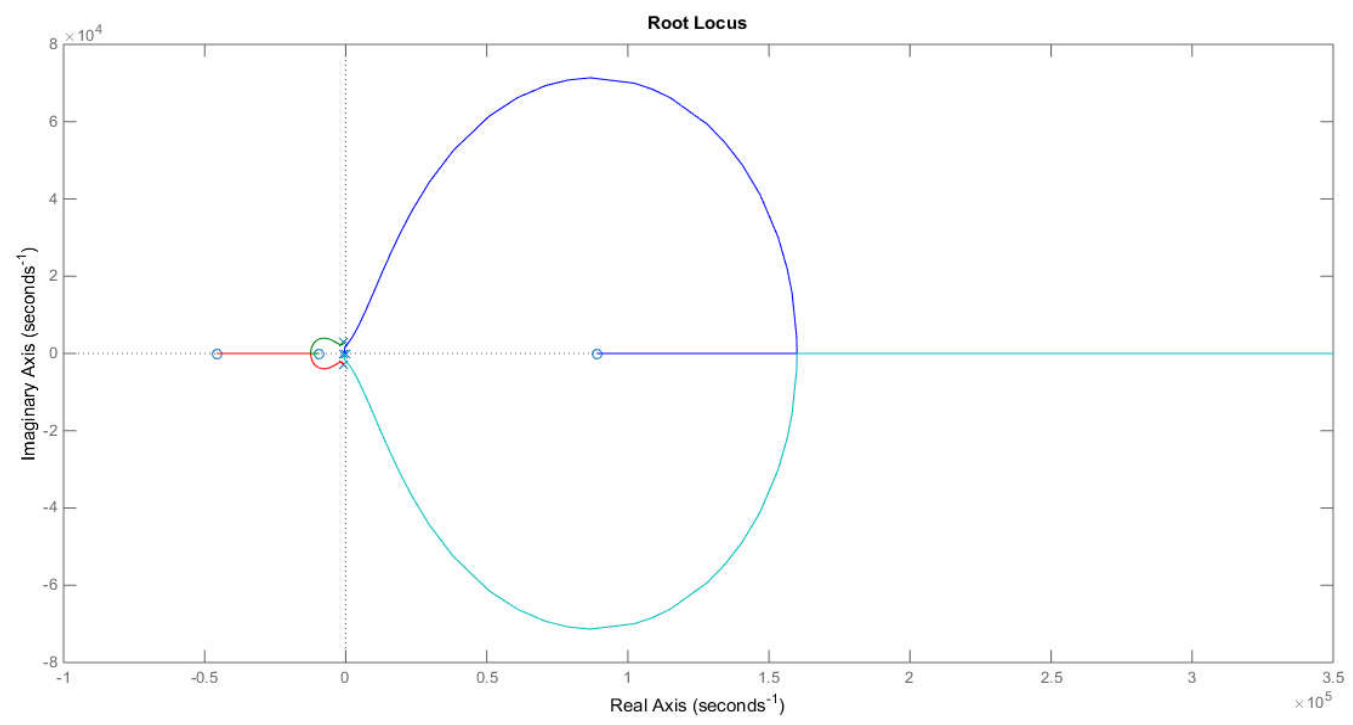

Figure 17: Root locus of the complete closed loop transfer function of the boost regulator and the designed controller (Equation (19)). 


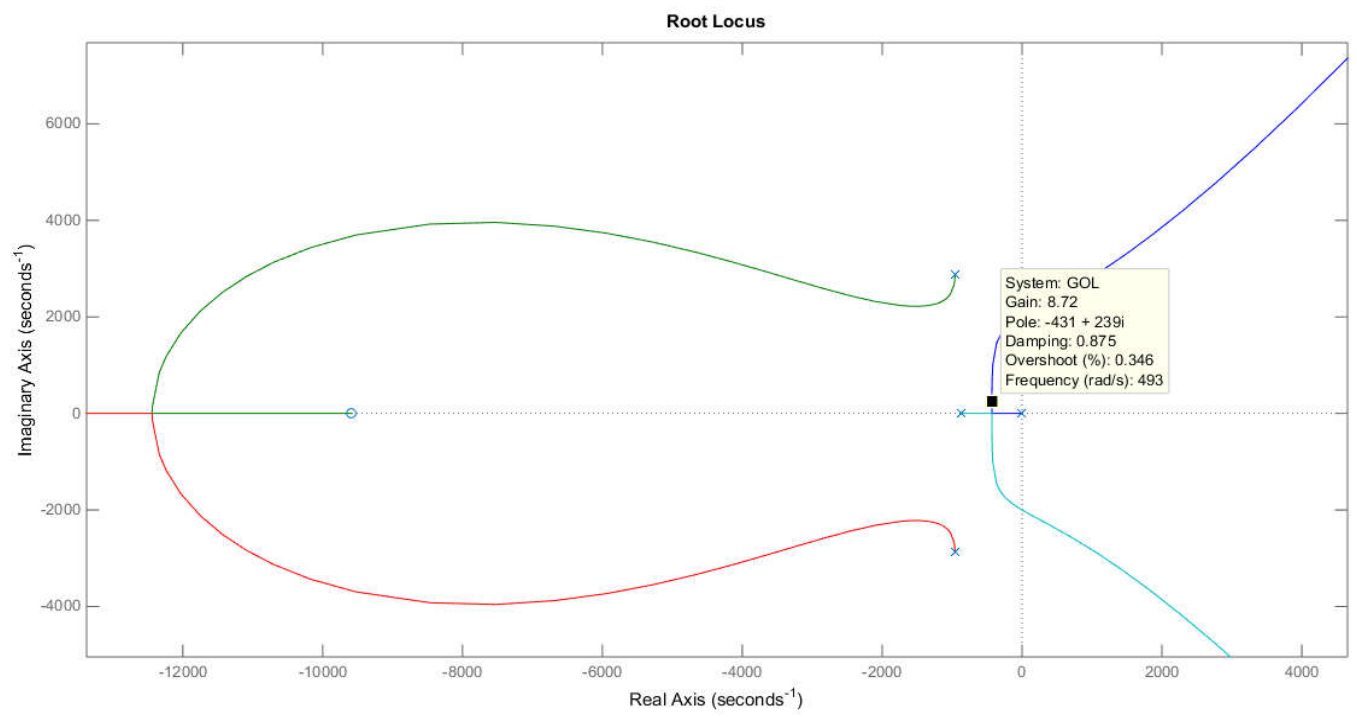

Figure 18. Zoom of the root locus of the closed loop system with designed controller (Equation (19)) around the origin.

The Bode diagram of the closed system with designed controller has been shown in figure 19. The gain margin and phase margin of the system are $40.8 \mathrm{db}$ and 87.7 degree respectively.

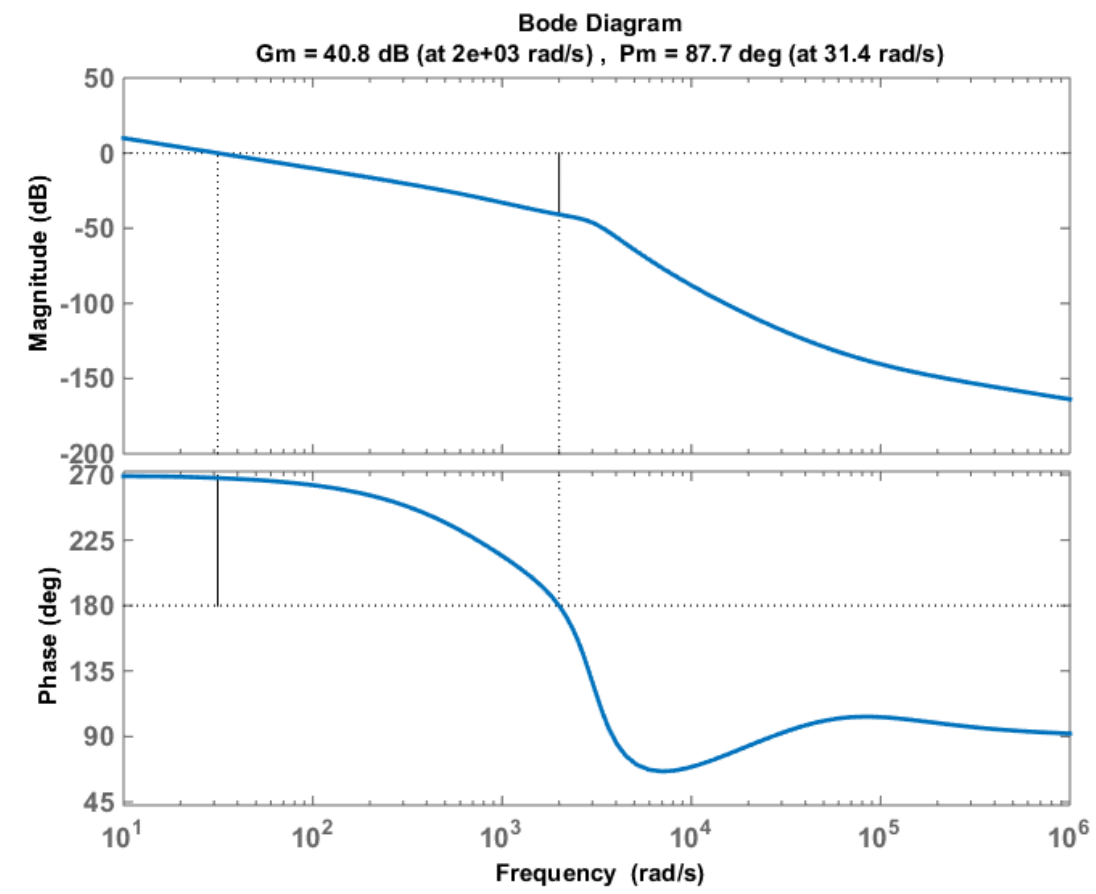

Figure 19. The Bode diagram of the boost regulator and the designed controller. 


\section{SIMULATION OF THE DESIGNED BOOST CONVERTER CIRCUIT}

The simulation of the converter has been done in two sections. At first, the block diagrams of the converter and designed controller have been simulated in the MATLAB Simulink environment. The figure 20 shows this representation. In second part, the electronic circuit of the converter has been considered in the PLECS software. To show the merit of the designed controller and its electronics equivalent, three schemes have been considered to check the tracking error and disturbance rejection.

1- The system power key is connected at the first moments of the simulation on $t=0 \mathrm{~s}$. The output voltage must tend to the $19 \mathrm{~V}$ as soon as possible.

2- A $3 \mathrm{~V}$ sudden rise and drop in the converter input voltage $\left(v_{G}\right)$ are befallen at $100 \mathrm{~ms}$ and $150 \mathrm{~ms}$, respectively. These disturbances must be compensated by the controller so that the output voltage can come back to the desired output $19 \mathrm{~V}$ with minimum overshoot, oscillation and settling time.

3- A 3 A sudden rise and drop in the convertor output current have been betided at $250 \mathrm{~ms}$ and $280 \mathrm{~ms}$, respectively. These scenarios are done in the PLECS environment by decreasing and increasing the load resistance.

The output voltage deviations, changes of the convertor duty cycle (controller output) and the inductor current deviations have been shown in Figure 21 through Figure 23 in MATLAB Simulink environment respectively.

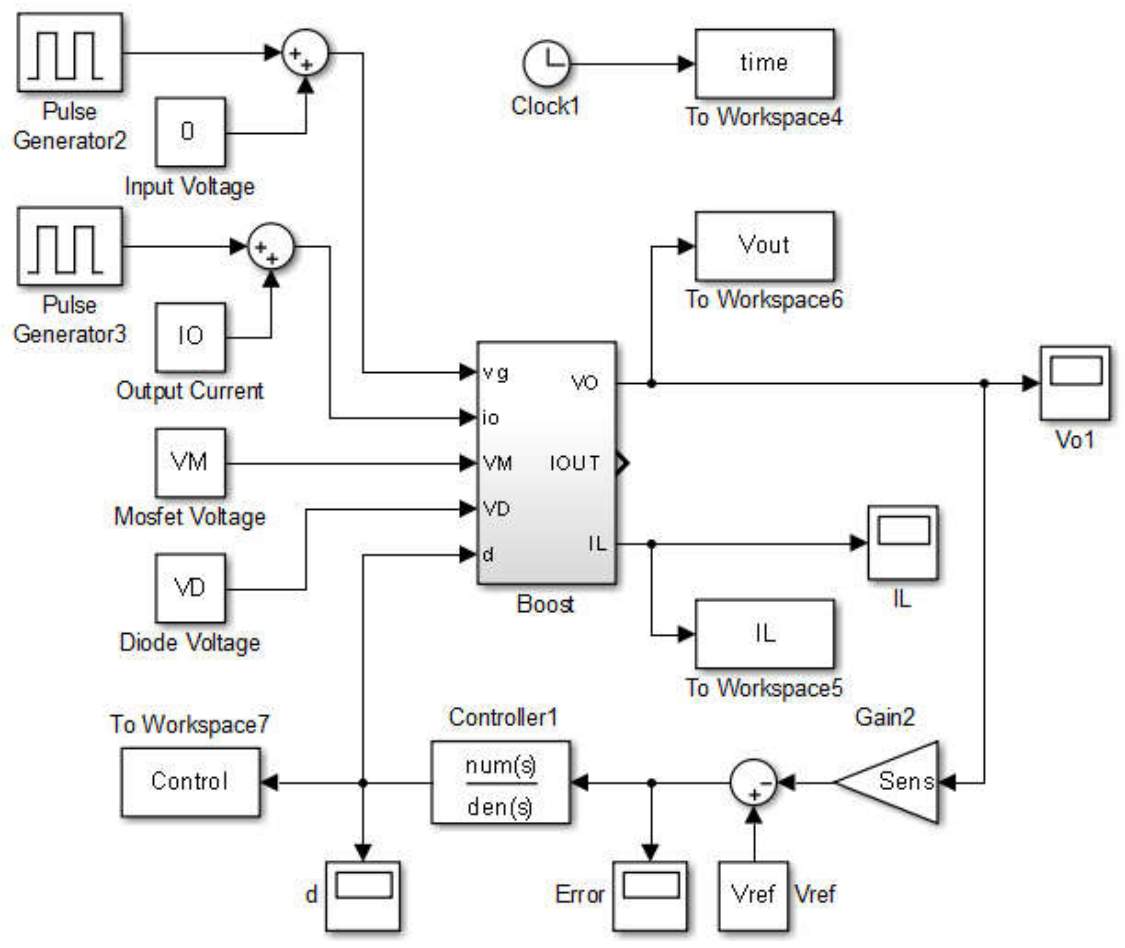

Figure 20: The closed loop system of the boost converter and designed controller in MATLAB Simulink environment. 


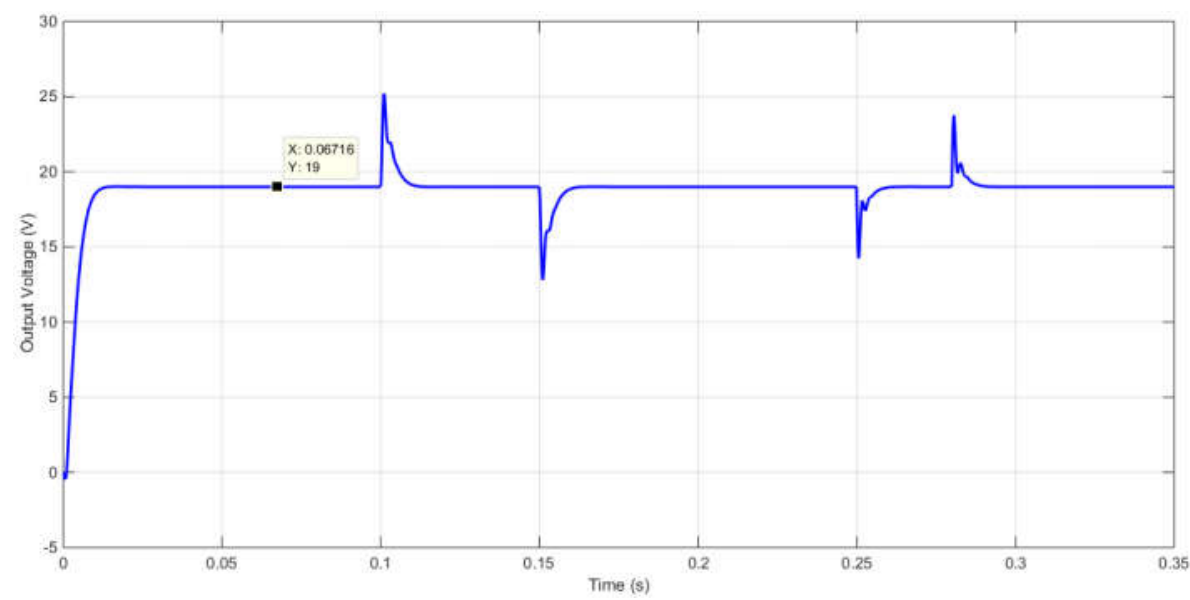

Figure 21. The output voltage deviations in MATLAB Simulink environment.

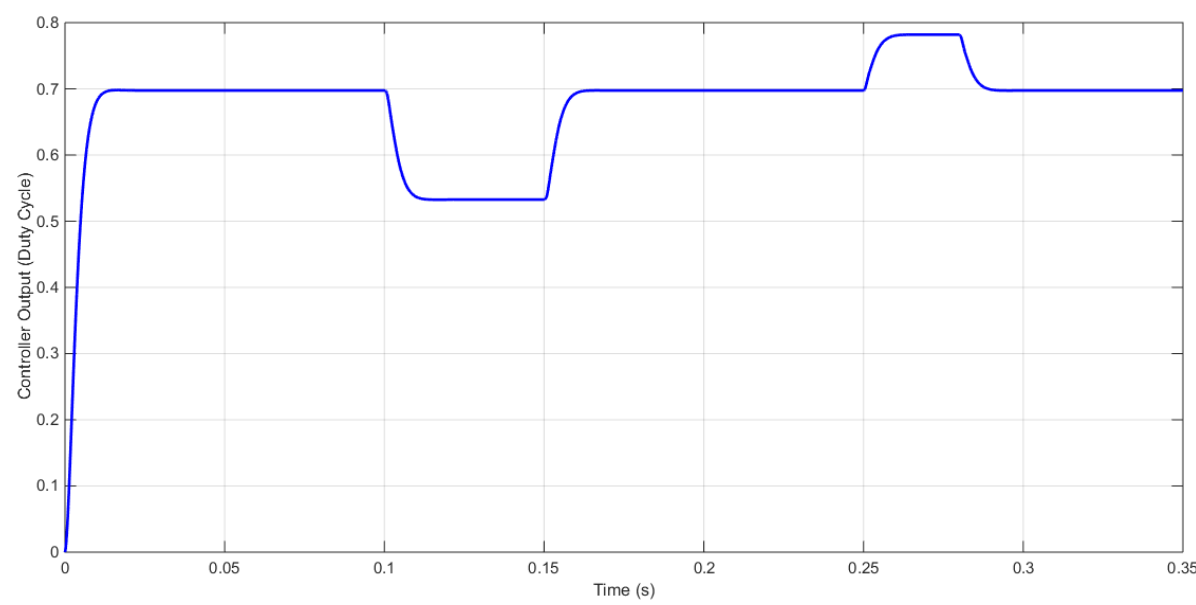

Figure 22. The duty cycle deviations in the MATLAB Simulink environment.

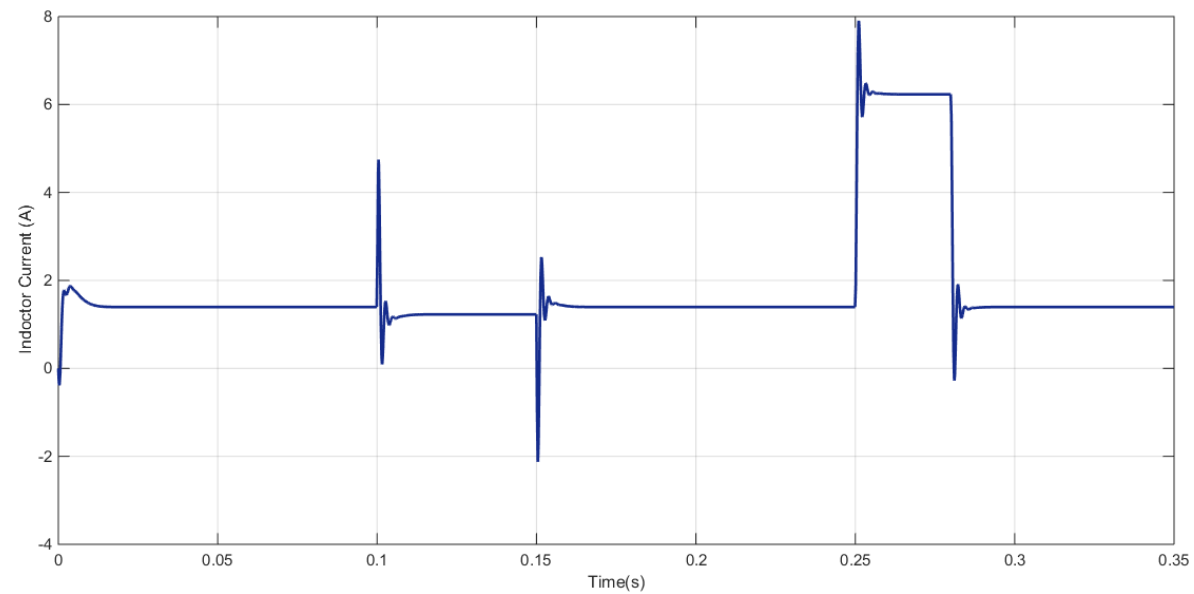

Figure 23. The inductor current deviations in the MATLAB Simulink environment.

Also, to check the accuracy of the actual electronic circuit of the system, the boost converter, along with the designed electronic controller according to figure 24 
has been simulated in the PLECS software. A scenario has been defined to check the performance of the controller, such as MATLAB software. The variation of the output voltage of the converter, the rate of duty cycle changes (electronic controller output) and the inductor current variations have been shown in Figure 25 through figure 27 successively. As can be seen, apart from the transient motion of the simulations, the overall structures of their results are similar and the outputs are set to $19 \mathrm{~V}$. It is noteworthy that the intended changes for the input voltage is $3 / 12=25 \%$ and for the load current of about $3 / 19.44=700 \%$. These variations have been considered so high to indicate the proper performance of the controller.

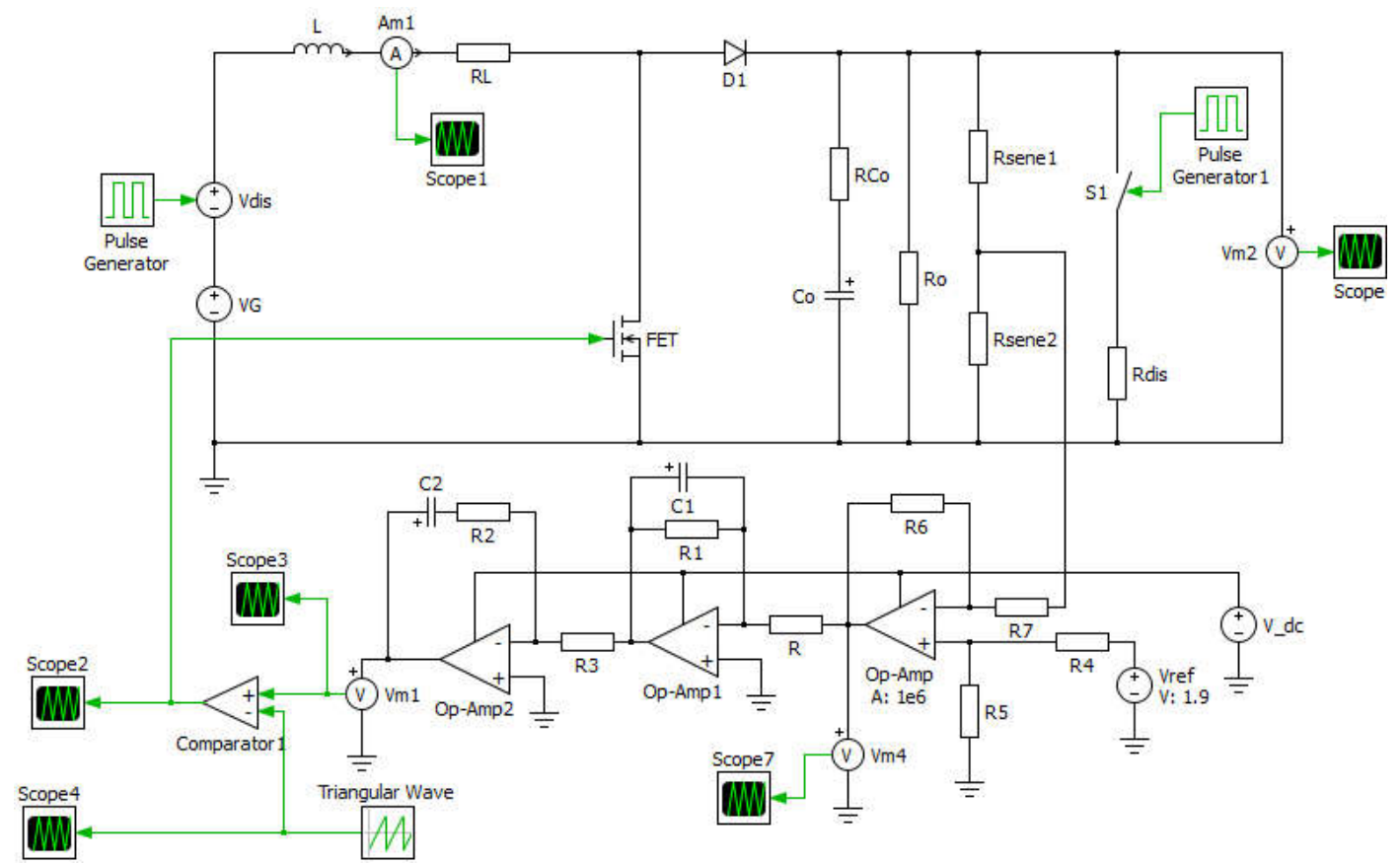

Figure 24. The electronic circuit of the boost converter and designed controller in the PLECS software.

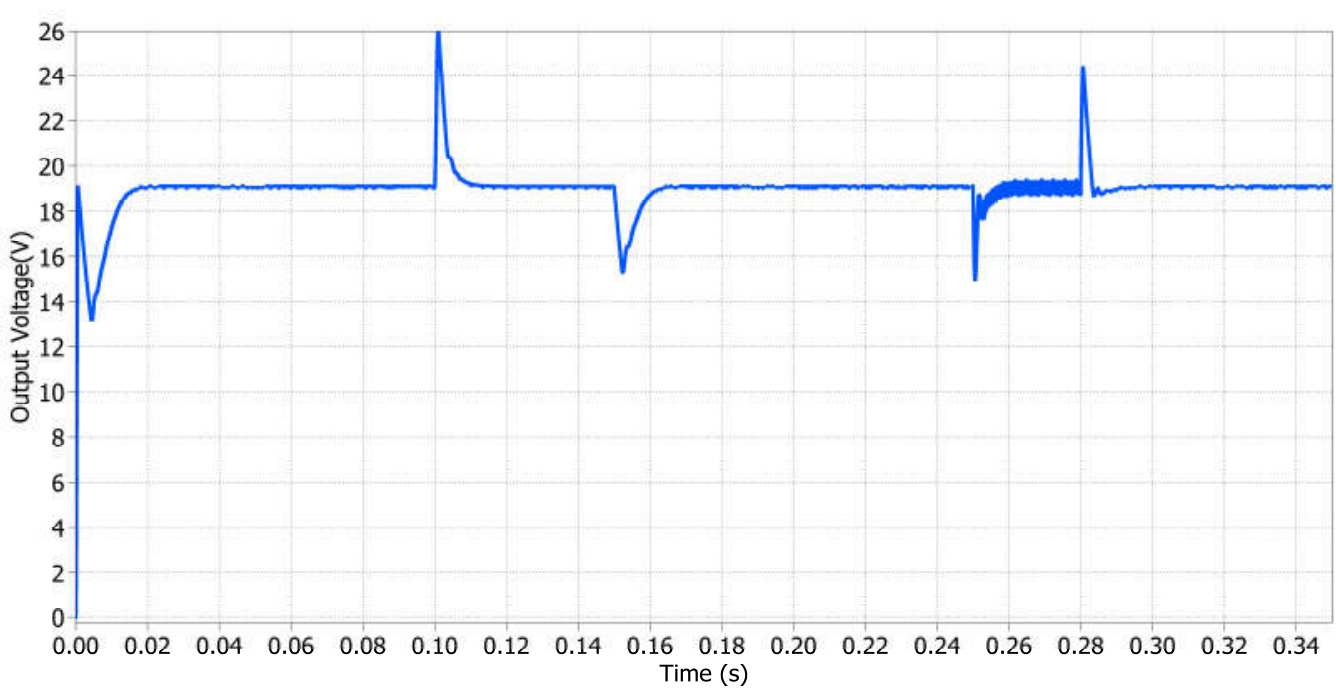

Figure 25. The output voltage deviations in the PLECS software. 


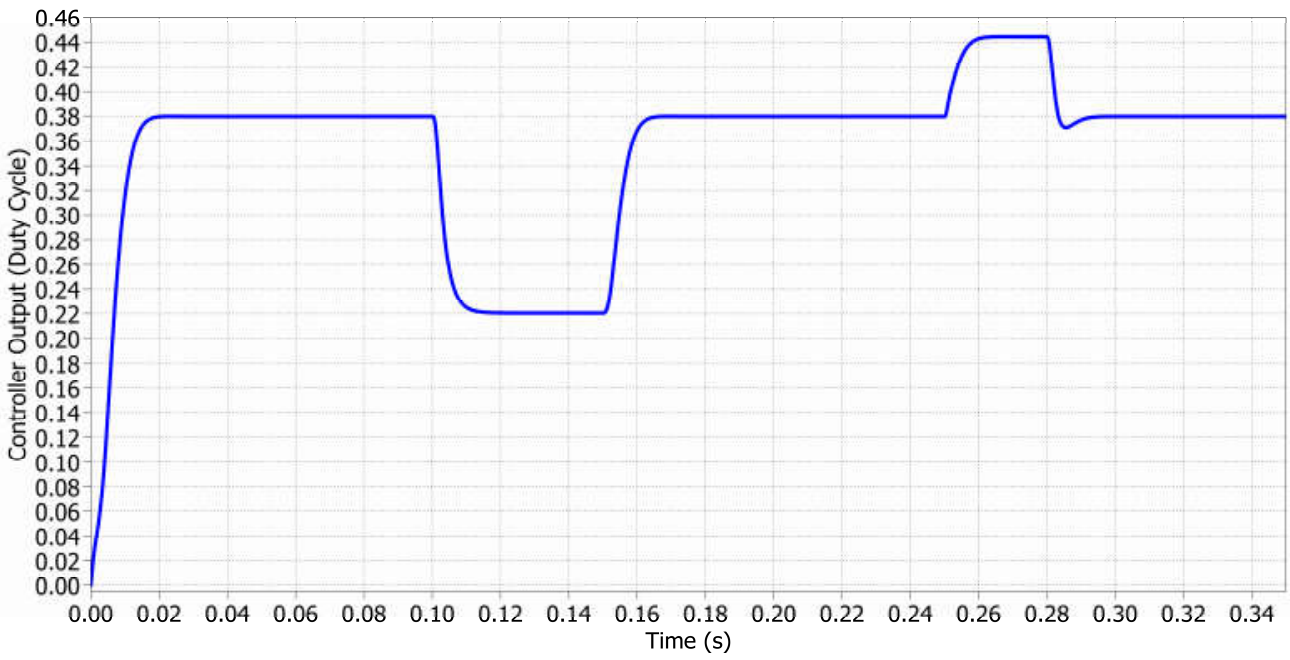

Figure 26. The duty cycle deviations in the PLECS software.

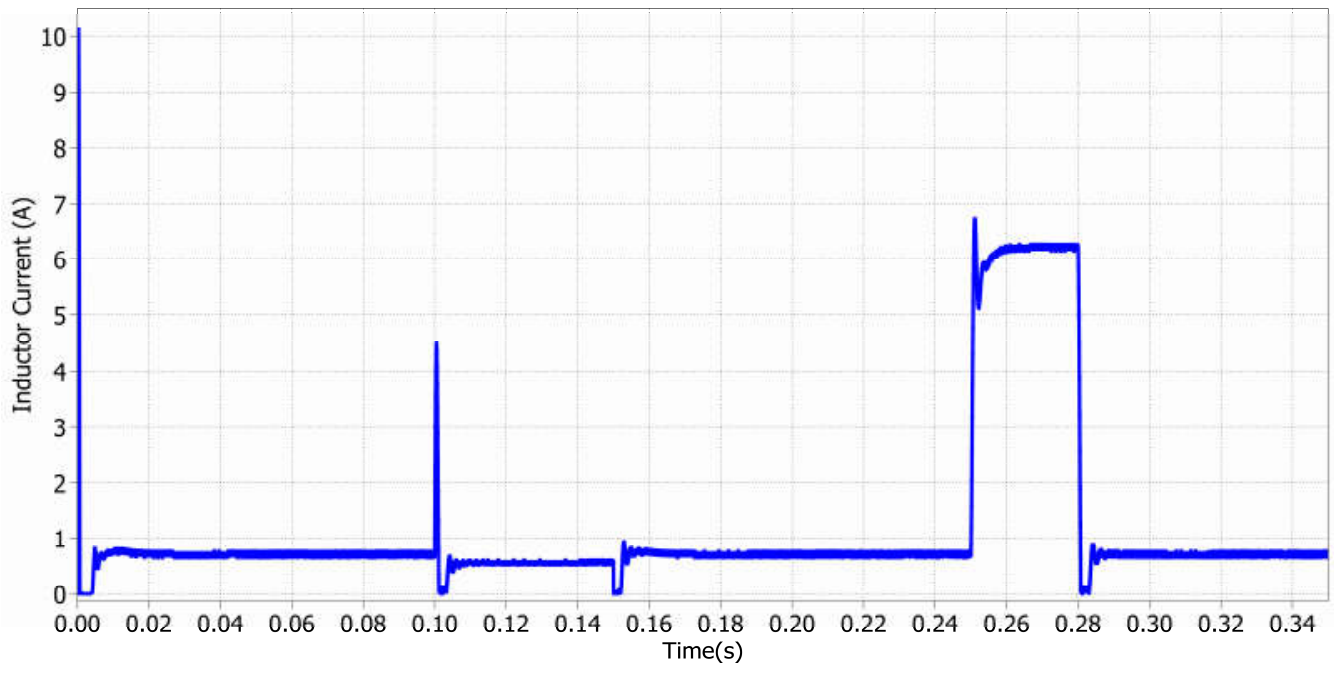

Figure 27. The inductor current deviations in the PLECS software.

\section{CONCLUSION}

In this paper, at first the complete state space model of the non isolated DC-DC boost converter has been introduced in the presence of the on state voltage drop, resistance of the diode and active switch, parasitic resistance of the inductor and capacitor and unknown load current. Eliminating these uncertainties, the simple transfer functions of converter from the output voltage to the input voltage and duty cycle control input have been calculated. Based on these transfer functions and root locus method, a second degree controller has been designed to stabilize the output voltage of the controller. A step by step manner has been introduced to select the values of this controller's gain and its pole and zero locations based on the complete state space of the boost regulator. Also, the electronic circuit of this controller has been synthesized by operational amplifiers. The parameters values of the designed controller and its electronic circuit have been presented for a $12 \mathrm{~V}$ to $19 \mathrm{~V}$ nonisolated DC-DC converter by considering the complete state space model. At the end, to show the merit of the designed controller, the system block diagram and its 
electronics equivalent circuit have been simulated in response to the input voltage deviations and load current changes of the converter in the MATLAB Simulink environment and PLECS software respectively. The construction and procedure that have been introduced to design the controller and its equivalent electronic circuit can be used for other basic switching regulators like as buck and buck-boost.

\section{Acknowledgements}

Authors would like to appreciate the Technical and Vocational University (TVU) for its supports to do this work.

\section{REFERENCES}

[1] N.Mohan, T. M. Undeland, and W. P. Robbins, Power Electronics, Converters, Applications, and Design, John Wiley \& Sons, 2003, pp.161.

[2] R. Erickson, DC-DC Converter, Article in Wiley Encyclopedia of Electrical and Electronics Engineering, 2008.

[3] V. I. Utkin, Sliding Mode Control Design Principles and Applications to Electric Drives, IEEE Trans. on Industrial Applications, Vol. 40, pp. 23-36, 1993.

[4] J.H. Su, J.J. Chen, and D. S. Wu, Learning Feedback Controller Design of Switching Converters via MATLAB/SIMULINK, IEEE Trans. on Education, Vol.45, pp. 307-315,2002.

[5] R. B. Ridley, A New Continuous-Time Model for Current -Mode Control, IEEE Trans. on Power Electronics, Vol. 6, No. 2, PP. 71-280, 1991.

[6] P. Li, and B. Lehman, A Design Method for Paralleling Current Mode Controlled DC-DC Converters, IEEE Trans. On Power Electronics, Vol. 19, pp. 748-756, May 2004.

[7] R. D. Middlebrook, and R S.cuk. A General unified Approach to Modelling switching converter power stages, IEEE PESC,1976 Record, pp 18-34.

[8] C.P.Basso, Switch-mode power supply spice cookbook, McGrawHill,2001,ISBN0-07-137509-0, pp 10-13

[9] B. Tamescu, On the Use of Fuzzy Logic to control Paralleled DC-DC Converters, PHD Thesis, Blackbury, Virginia Polytechnic Institute and State University, October 2001.

[10] R. Naim, G. Weiss, and S. Ben-Yaakov, $H^{\infty}$ Control Applied to Boost Power Converters, IEEE Trans. on Power Electronics, vol. 12, no. 4, July 1997, pp. 677-683.

[11] V. Vorperian, Simplified Analysis of PWM Converters Using the Model of the PWM Switch, Parts I (CCM) and II (DCM), Trans. on Aerospace and Electronics systems, vol. 26, no. 3 May 1990.

[12] V. Vorperian, Fast analytical techniques for ELECTRICAL and ELECTRONIC CIRCUITS, CAMBRIDGE UNIVERSITY PRESS, 2004, ISBN 0-521-62442-8

[13] A. Romero, Circuito Integrade de Control Deslizante Para Convertidores Conmutados Continua, Tesis Doctoral (en Realizacion). Department d'Enginyeria Electeronica Universital Polictecnica de Catalunya, 2001.

[14] C. M. Ivan, D. Lascu, and V. Popescu, A New Averaged Switch Model Including Conduction Losses PWM Converters Operating in Discontinuous Inductor Current Mode, SER. ElEC ENERG. Vol. 19, No. 2, August 2006, PP 219-230. 
[15] Modabbernia, M. R.; Sahab, A. R.; Mirzaee, M. T. \& Ghorbany, K. (2012), The state space average model of boost switching regulator including all of the system uncertainties, Advanced Materials Research, vol. 403, pp. 34763483. 